\title{
Purification of Nitrate Contaminated Aqueous Solution Using Modified and Unmodified Palmkernel Shell
}

\author{
O.L. Adebayo ${ }^{1 *}$, A.A. Adaramodu ${ }^{1}$, M.G. Ajayi ${ }^{1}$, F.E. Olasehinde ${ }^{2}$ \\ and J.G. Oyetunde ${ }^{1}$ \\ ${ }^{1}$ Department of Chemistry, College of Education, Ikere. Ekiti State, Nigeria \\ ${ }^{2}$ Department of chemical Science, Federal University of Technology, \\ Akure, Ondo State, Nigeria \\ *femtay41@yahoo.co.uk
}

Keywords: Nitrate, Palmkernel shell,Thermoactivation, Adsorption, Methemoglobin.

\begin{abstract}
The adsorption capacity of PKS which was used as an adsorbent in this study was boosted by acid thermoactivation. The nitrate sorption potential, point zero charge (PZC) and surface area of the PKS were enhanced by the acid thermoactivation process. The process of sorption of nitrate from solution was analyzed using five different isotherm models [Langmuir, Freundlich, Temkin, Harkins-Jura, and Halsey isotherm equations]. The value of the Langmuir monolayer sorption capacity qm [mg/g] increased from 60.12 to 85.73 , PZC values increased from 5.50 to 8.40 , and the surface area $\left[\mathrm{m}^{2} / \mathrm{g}\right.$ ] value increased from $29 \mathrm{~m}^{2} / \mathrm{g}$ to $98 \mathrm{~m}^{2} / \mathrm{g}$ after the activation process. The effect of $\mathrm{pH}$ on the sorption of the nitrate on both sorbents was also considered and it was discovered that the adsorption of nitrate decreases with increase in nitrate solution $\mathrm{pH}$. The effects of the sorbents dose on the sorption process was also studied and the results showed that the amount of nitrate sorbed by both sorbent decreases with increase in sorbent dose.
\end{abstract}

\subsection{Introduction}

Water pollution is the contamination of natural water bodies by chemical, physical, radioactive or pathogenic microbial substances. Adverse alteration of water quality presently produces large scale illness and deaths, accounting for approximately 50 million deaths per year worldwide, most of these deaths occurring in Africa and Asia. In China, for example, about 75 percent of the population (or 1.1 billion people) are without access to unpolluted drinking water, according to China's own standards [1]. Widespread consequences of water pollution upon ecosystems include species mortality, biodiversity reduction and loss of ecosystem services. Some consider that water pollution may occur from natural causes such as sedimentation from severe rainfall events; however, natural causes, including volcanic eruptions and algae blooms from natural causes constitute a minute amount of the instances of world water pollution. The most problematic of water pollutants are microbes that induce disease, since their sources may be construed as natural, but a preponderance of these instances result from human intervention in the environment or human overpopulation phenomena.

Chemical water pollutants are generally atoms or molecules, which have been discharged into natural water bodies, usually by activities of humans [2]. Common examples of such chemical water pollutants are mercury emanating from mining activity, certain nitrogen compounds used in agriculture, chlorinated organic molecules arising from sewage or water treatment plants [2] or various acids which are the externalities of various manufacturing activities. Nitrates are the oxidized form of nitrogen derived from nitrogenous compounds produced by plant and animals or the mining of sodium nitrate for use in fertilizers, and the atmosphere. The presence of nitrate ions in the polluted water has become a major threat for infants younger than 6 months of age since they are very susceptible to methemoglobiemia [3,4,5], a condition known as "blue baby syndrome". Due to the fact that nitrate is a stable, highly soluble ion, it is difficult to remove by conventional processes [6]. However, most conventional waste water treatment techniques for removal of nitrate 
such as chemical and biological denitrification, reverse osmosis, electodyalisis and ion exchange are not economically viable for small scale industries due to huge capital investment [7]. It is therefore necessary to search for low-cost techniques that may be effective, less environmentally degrading and economical for industrial usage. Adsorption has been shown to be an economically feasible alternative method for removing nitrate from waste water and water supplies [8]. This process involves the transfer of liquid-phase solutes to solid-phase adsorbents [9], and it is often adopted in waste water treatment and water purification because of its simplicity and low operational cost. During adsorption, pollutants are sorbed onto the sorbent surface from the aqua medium. The amount of pollutant sorbed by the sorbent depends largely on the adsorption capacity of the solid sorbent [10].

Palm kernel shell is an agricultural waste product in the production of palm oil from the palm kernel fruit. The use of agricultural by- products for the sorption of valuable metals from waste water has continued to attract considerable attention because they are cheap source of biosorbents, sludge free and involve small initial cost and land investment [8]. These includes the use of numbers of agricultural materials such as sugar cane cabon [11], spent grain [12], rice husk [13], Cassava waste [8], Groundnut [15], wild cocoyam biomass [8], wheat bran [15].

The aim of this study suggest the possibility of developing good adsorbents from agricultural waste and asses the adsorption potential of palm-kernel shell to adsorb nitrate ions from aqueous solutions.

\subsection{Materials and Methods}

\subsection{Sorbate preparation (Nitrate)}

A stock solution of $100 \mathrm{mg} / \mathrm{L}$ of nitrate will be prepared by dissolving $0.16 \mathrm{~g}$ of $\mathrm{KNO}_{3}$ in a litre of distilled water using standard volumetric flask. Different working solutions were prepared from the stock solution by serial dilution.

\subsection{Sorbate quantification (Nitrate)}

The nitrate concentrations in the aqueous medium were quantified by the determination of the absorbance at the characteristic wavelength using a double beam UV/visible spectrophotometer. A standard solution of the nitrate was taken and the absorbance was determined at different wavelengths to obtain a plot of absorbance versus wavelength. The wavelength corresponding to the maximum absorbance ( $\lambda \max$ ), as determined from this plot, was noted and the wavelength was used for the preparation of the calibration curve used in the present studies.

\subsection{Sorbent Preparation}

The PKS sample used in this investigation was collected from a palm oil company located in Ado Ekiti in Ekiti State, Nigeria. The raw PKS was steeped in warm deionized water $(500 \mathrm{~g} / \mathrm{L}$ warm water) for about 30 minutes to melt the residual oil on it. The PKS was separated from the warm deionized water and washed with $0.5 \mathrm{M} \mathrm{NaOH}$ for alkaline hydrolysis (saponification) of any residual oil on it. The saponified PKS was thoroughly washed until the foaming stopped and its $\mathrm{pH}$ was equal to the $\mathrm{pH}$ of the deionized water used in washing. The PKS was oven-dried, ground, and screened through a set of sieves to obtain particles size 53-74 $\mu \mathrm{m}[16]$. The modified PKS was obtained from a pulverized PKS by acid thermoactivation which is a process that allows an acceptable acidity level in the palm kernel shell. In the thermoactivation [17] process, the pulverized PKS was put in a flask with an acid solution $(10 \mathrm{~mL}$ acid/1 g PKS), under stirring and reflux and heated to $95{ }^{\circ} \mathrm{C}$ for $2 \mathrm{~h}$. Afterwards, the PKS was washed with de-ionized water until neutral $\mathrm{pH}$ is obtained and dried at $60{ }^{0} \mathrm{C}$ to constant weight. The powders were further pulverized to a particle size of $0.45 \mathrm{~mm}$ and then heated for $2 \mathrm{~h}$ at $200^{\circ} \mathrm{C}$.

\subsection{Characterization of the sorbents}

The modified and unmodified PKS samples were characterized thus: specific surface area was determined using the method of Sear's and the point zero charge (PZC) was determined by solid addition method. 


\subsection{Adsorption experiment}

The effect of acid thermoactivation on the sorption capacity of the PKS materials for nitrate was evaluated via equilibrium isotherm analysis. The sorption capacities of the modified and unmodified PKS were determined by contacting $50 \mathrm{~mL}$ solution of known nitrate concentration that ranged between 50 and $500 \mathrm{mg} / \mathrm{L}$ with $0.2 \mathrm{~g}$ of each of the adsorbents (i.e. modified and unmodified PKS). The mixture was stirred at $200 \mathrm{rpm}$ in thermostatic shaker for $2 \mathrm{~h}$, samples were removed, centrifuged, and the supernatant was analyzed for residual nitrate with a UV-visible spectrophotometer. The amount of nitrate sorbed per unit mass of the adsorbent (in $\mathrm{mg} / \mathrm{g}$ ) was calculated using the mass balance equation as given by:

$$
q_{t}=\mathrm{V}\left(\mathrm{C}_{\mathrm{o}}-\mathrm{C}_{\mathrm{f}}\right) / \mathrm{m}
$$

where: $\mathrm{q}_{\mathrm{t}}=$ amount of nitrate adsorbed $\left(\mathrm{mg} \mathrm{g}^{-1}\right)$ at various time $(\mathrm{t}), \mathrm{C}_{0}=$ initial concentration of the sorbate $(\mathrm{mg} / \mathrm{L}), \mathrm{C}_{\mathrm{f}}=$ final concentration of the sorbate $(\mathrm{mg} / \mathrm{L}), \mathrm{m}=$ mass of the sorbent $(\mathrm{mg}), \mathrm{V}$ is the volume of the sorbate used (L).

The sorption process variables were optimized thus: the effect of $\mathrm{pH}$ on the sorption process was investigated by varying the $\mathrm{pH}$ of the initial nitrate solution from $\mathrm{pH} 2$ - to $\mathrm{pH} 12$; the effect of adsorbents dose was studied at different dosage of $0.2,0.4,0.6,0.8$ and $1.0 \mathrm{~g}$ of the sorbents in contact with fixed nitrate solution of $500 \mathrm{mg} / \mathrm{L}$. The mixture in the flask was shaken at $220 \mathrm{rpm}$ for $2 \mathrm{~h}$ and the equilibrium concentration of the residual nitrate was determined spectrophotometrically.

\subsection{Results and Discussion}

\subsection{Characterization of modified and unmodified PKS}

The modification of the PKS produced a material whose PZC value (8.40) was greater than that of the unmodified PKS (5.50). Values of PZC that ranged between 3.0 and 7.5 have been reported for PKS shell. The higher value of the PZC obtained for the modified PKS could be ascribed to the acid thermoactivation of the PKS framework, which possibly modified the surface charge of the PKS. The results of the specific surface area of the PKS showed that the modified PKS had higher specific surface area $\left(98 \mathrm{~m}^{2} / \mathrm{g}\right)$ than that of the unmodified PKS $\left(29 \mathrm{~m}^{2} / \mathrm{g}\right)$. The higher specific surface area of the modified PKS could be ascribed to the acid modification of the PKS which opened up the layers and the pores.

\subsection{Equilibrium isotherm studies}

The equilibrium relationship between the concentration of the nitrate in the fluid phase and the nitrate in the modified and unmodified PKS at a given temperature was studied. The isotherm parameters obtained, using the following linearized models of Langmuir, Freundlich, Temkin, Halsey and Harkins-Jura isotherm models are presented in Table 1 and 2 respectively.

$$
\begin{aligned}
& \text { Langmuir: } \frac{C_{e}}{q_{e}}=\frac{1}{K q_{m}}+\frac{1}{q_{m}} C_{e} . \\
& \text { Freundlich }: \log q_{e}=\log K_{f}+\frac{1}{n} \log C_{e} . \\
& \text { Temkin: } q_{e}=B_{1} \ln K T+B_{1} \ln C_{e} . \\
& \text { Halsey: } \ln q_{e}=\frac{1}{n} \ln K-\frac{1}{n} \ln C_{e} . \\
& \text { Harkin- Jura }: \frac{1}{q_{e}^{2}}=\left(\frac{B}{A}\right)-\frac{1}{A} \log C_{e} .
\end{aligned}
$$

The ability of both sorbents to adsorb nitrate from the aqueous medium was assessed via equilibrium isotherm analysis at different initial nitrate concentrations. The values of the monolayer sorption capacities, qm (mg/g), obtained from Langmuir plot of sorption data of unmodified PKS (60.12) were lower than that of modified PKS (85.73). The magnitude of Langmuir constant, $\mathrm{K}_{\mathrm{L}}$, 
which is the sorption equilibrium constant $\left(\mathrm{dm}^{3} / \mathrm{mg}\right)$, was also lower (0.9674) in the unmodified PKS than in the modified PKS (1.4523). The higher the magnitude of the heat of sorption, the stronger the bond formed between the sorbate and the sorbent.

The values of the Freundlich constants, $\mathrm{kf}$ and $1 / \mathrm{n}$, which are Freundlich affinity coefficient and Freundlich linearity index respectively obtained from the plot of log qe vs $\log \mathrm{Ce}$, are presented in Table 1 and 2 for both sorbents. As shown in the Tables, the value of $K_{f}$ for unmodified PKS is lower in comparison with modified PKS which implied that the modification of PKS by acid thermoactivation produced more suitable conditions for nitrate sorption. Also the value of $1 / n$, which is less than unity for modified PKS (0.9788) shows the favorable nature of adsorption of nitrate on PKS.

The Temkin constants, $\mathrm{K}_{\mathrm{T}}$ which is the equilibrium binding constant $(\mathrm{L} / \mathrm{mol})$ corresponding to the maximum binding energy and B1which is related to the heat of adsorption obtained from the plot of qe vs $\ln$ Ce for modified and unmodified PKS are presented in Table 1 and 2. The value of Temkin constant, $B 1$, for modified (9.878) and unmodified (8.845) obtained from the Temkin plot showed that the sorption process is an endothermic process. More so, the poor value of the linear coefficient $\left(\mathrm{r}^{2}\right)$ for modified $(0.8567)$ and unmodified (0.8156) PKS is an indication of the low interaction between the nitrate molecules adsorbed on the PKS surface.

The Harkin's Jura isotherm equation accounts for multilayer adsorption and can be explained with the existence of a heterogeneous pore distribution. The Harkins- Jura isotherm parameters were obtained for both sorbent (Table 1 and 2) from the plots of 1/qe2 against log Ce. The low value of the linear coefficient for modified $\left(r^{2}=0.7629\right)$ and unmodified $\left(\mathrm{r}^{2}=0.7352\right)$ PKS could be ascribed to the fact that the distribution of the pores on the PKS surface was more homogeneous than heterogeneous.

The Halsey isotherm parameters were obtained from the plot of lnqe versus $\ln$ Ce for both sorbents (Table 1and 2). The Halsey isotherm equation is suitable for multilayer adsorption and the fitting of the experimental data to this equation attests to the heteroporous nature of the adsorbent [18].

Table 1. Equilibrium Isotherm Parameters of sorption of nitrate on modified PKS.

\begin{tabular}{ccccccccc}
\hline \multicolumn{2}{c}{$\begin{array}{c}\text { Langmuir Isotherm } \\
\text { Parameter }\end{array}$} & \multicolumn{2}{c}{$\begin{array}{c}\text { Freudlich Isotherm } \\
\text { Parameter }\end{array}$} & $\begin{array}{c}\text { Temkin } \\
\text { Isotherm }\end{array}$ & $\begin{array}{c}\text { Harkins } \\
\text { Jura }\end{array}$ & $\begin{array}{c}\text { Halsey } \\
\text { Isotherm }\end{array}$ \\
\hline $\mathrm{qm}$ & $\mathrm{K}_{\mathrm{L}}$ & $\mathrm{r}^{2}$ & $\mathrm{k}_{\mathrm{f}}$ & $1 / \mathrm{n}$ & $\mathrm{r}^{2}$ & $\mathrm{~B} 1=9.878$ & $\mathrm{~A}=11.72$ & $\mathrm{n}=1.3752$ \\
{$[\mathrm{mg} / \mathrm{g}]$} & {$\left[\mathrm{mg}^{-1}\right]$} & & {$[1 / \mathrm{g}]$} & & & $\mathrm{K}_{\mathrm{T}}$ & $\mathrm{B}=0.62$ & $\mathrm{~K}=163.5$ \\
85.73 & 1.4523 & 0.998 & 60.75 & 0.9788 & 0.999 & $\begin{array}{c}\left.{ }^{2} / \mathrm{mg}\right]=31.84 \\
\mathrm{r}^{2}=0.8567\end{array}$ & $\mathrm{r}^{2}=0.7629$ & $\mathrm{r}^{2}=0.999$ \\
& & & & & \multicolumn{3}{c}{} \\
\hline
\end{tabular}

Table 2. Equilibrium Isotherm Parameters of sorption of nitrate on unmodified PKS.

\begin{tabular}{ccccccccc}
\hline \multicolumn{2}{c}{$\begin{array}{c}\text { Langmuir Isotherm } \\
\text { Parameter }\end{array}$} & & \multicolumn{2}{c}{$\begin{array}{c}\text { Freudlich Isotherm } \\
\text { Parameter }\end{array}$} & $\begin{array}{c}\text { Temkin } \\
\text { Isotherm }\end{array}$ & $\begin{array}{c}\text { Harkins } \\
\text { Jura }\end{array}$ & $\begin{array}{c}\text { Halsey } \\
\text { Isotherm }\end{array}$ \\
\hline $\mathrm{Qm}$ & $\mathrm{K}_{\mathrm{L}}$ & $\mathrm{r}^{2}$ & $\mathrm{k}_{\mathrm{f}}$ & $1 / \mathrm{n}$ & $\mathrm{r}^{2}$ & $\mathrm{~B} 1=8.845$ & $\mathrm{~A}=10.65$ & $\mathrm{n}=0.9863$ \\
{$[\mathrm{mg} / \mathrm{g}]$} & {$\left[\mathrm{mg}^{-1}\right]$} & & {$[1 / \mathrm{g}]$} & & & $\mathrm{K}_{\mathrm{T}}$ & $\mathrm{B}=0.61$ & $\mathrm{~K}=146.6$ \\
60.12 & 0.9674 & 0.984 & 32.51 & 1.3572 & 0.971 & $\begin{array}{c}{[1 / \mathrm{mg}]=37.79} \\
\mathrm{r}^{2}=0.8156\end{array}$ & $\mathrm{r}^{2}=0.7352$ & $\mathrm{r}^{2}=0.987$ \\
\hline
\end{tabular}

The linear coefficient of determinations, $r^{2}$, was used to evaluate the fitness of each isotherm equation to the experimental data obtained from the optimization process employed. The values of $\mathrm{r}^{2}$ obtained when the experimental data were fitted into Langmuir is 0.998 while Freundlich and Halsey isotherm equations is 0.999 for modified PKS while the unmodified PKS are 0.984, 0.971 and 0.987 respectively. The description of the sorption of nitrate on PKS by the Freundlich isotherm equations is an indication of the heterogeneity of the surface with a non-uniform distribution of heat of adsorption over the surface of the PKS, while the Halsey isotherm fitting is an indication of the heteroporosity of the surface and the multilayer adsorption nature of the nitrate on PKS. The results of the comparison of the Langmuir sorption capacity $\left(\mathrm{q}_{\mathrm{m}}\right)$ obtained from the present study with the values obtained by other researchers from the use of other sorbents for the removal of nitrate from 
aqueous solution is presented in Table 3. The result indicated that the modified PKS compared favorably with the other adsorbents that have been used and the Langmuir sorption capacity was higher than some of the other adsorbents.

Table 3. Comparison of adsorption capacity of modified and unmodified PKS with other adsorbents for nitrate removal.

\begin{tabular}{lcc}
\hline Adsorbents & qm $[\mathrm{mg} / \mathrm{g}]$ & References \\
\hline Modified PKS & 85.73 & Present study \\
Unmodified PKS & 60.12 & Present study \\
Activated carbon modified with $\mathrm{CaCl}_{2}$ & 1.93 & {$[19]$} \\
New clay & 250 & {$[20]$} \\
Sugar beet bagasse charcoal & 9.14 & {$[21]$} \\
$\mathrm{ZnCl}_{2}$ activated coir pith & carbon 10.30 & {$[22]$} \\
\hline
\end{tabular}

\subsection{Process variables}

\subsubsection{Effect of pH}

The nitrate solution $\mathrm{pH}$ optimization (Fig 1) showed a reduction in the magnitude of nitrate sorbed with increase in $\mathrm{pH}$ value and the amount of sorbate sorbed became negligible at the highest $\mathrm{pH}$ studied. Lower $\mathrm{pH}$ values favoured the removal of the nitrate moieties than higher $\mathrm{pH}$ values in both sorbents. The curves as shown in Fig. 1 revealed that nitrate adsorption on both samples could be linked to a simple anion/ $\mathrm{OH}^{-}$exchange reaction on the PKS surface. In the case of a simple anion exchange, anion uptake decreases monotonically with $\mathrm{pH}$ due to the increase of $\mathrm{OH}$ concentration and the change of surface charge to negative [23].

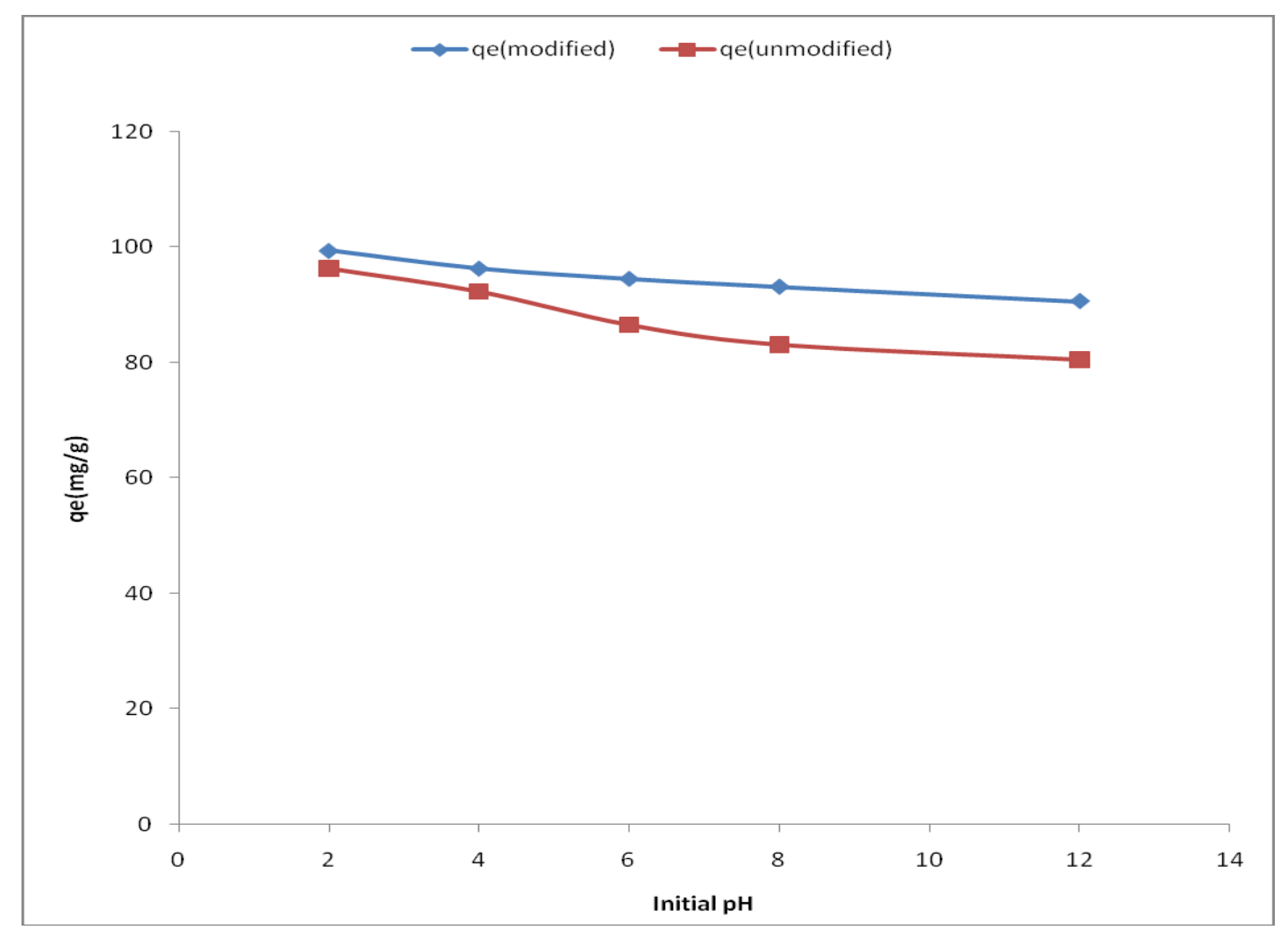

Figure 1. Effect of $\mathrm{pH}$ on the sorption of nitrate onto modified and unmodified PKS.

\subsubsection{Effect of adsorbent dosage}

The effect of both samples dosage on the sorption of nitrate was studied at the PKS dosage range of $0.2-1.0 \mathrm{~g} / \mathrm{L}$ at fixed nitrate concentration of $500 \mathrm{mg} / \mathrm{L}$, and a fixed agitation speed $(220 \mathrm{rpm})$ for $2 \mathrm{hrs}$ and the results are presented in Tables 4 and 5. These results showed instantaneous and equilibrium sorption capacities of nitrate are functions modified and unmodified PKS dosage. Increasing the dosage of both sorbents and keeping the nitrate concentration constant 
makes a large number of sites available for a fixed concentration of sorbate. Isotherm experiments were conducted and the data were analyzed using the linear forms of the Langmuir equation, to determine the effect of samples dosage on the nitrate removal from aqua medium. Isotherms were determined for five different PKS dosages ranges from $0.2-1.0 \mathrm{~g} / \mathrm{L}$ and the results obtained are presented in Table 4 and 5. The results showed that as the PKS dose was increased from 0.2 to $1.0 \mathrm{~g} / \mathrm{L}$, a reduction was observed in the values of the monolayer sorption capacities, $\mathrm{q}_{\mathrm{m}}$, from 85.73 to $20.68 \mathrm{mg} \mathrm{g}^{-1}$ for modified PKS while unmodified PKS reduced from 60.12 to $15.22 \mathrm{mg} \mathrm{g}^{-1}$. The reduction in the sorbent capacity with increase in dose could be attributed to two reasons: the increase in sorbent dose at constant nitrate concentration and volume will lead to unsaturation of sorption sites through the sorption process [24,25] and secondly may be due to particulates interactions. Such aggregation would lead to a decrease in total surface area of the sorbent and an increase in diffusional path length [24]. The value of the sorption equilibrium constant, $\mathrm{K}_{\mathrm{L}}$, increased with increase in the sorbent dose.

Table 4. Effect of modified PKS dosage on the sorption of nitrate.

\begin{tabular}{cccc}
\hline Sorbent dosage & $\mathrm{q}_{\mathrm{m}}$ & $\mathrm{K}_{\mathrm{L}}\left[\mathrm{mg}^{-1}\right]$ & $\mathrm{r}^{2}$ \\
\hline 0.2 & 85.73 & 1.4523 & 0.9932 \\
0.4 & 74.32 & 1.5764 & 0.9868 \\
0.6 & 50.66 & 1.6823 & 0.9958 \\
0.8 & 35.76 & 1.8753 & 0.9963 \\
1.0 & 20.68 & 1.9542 & 0.9877 \\
\hline
\end{tabular}

Table 5. Effect of unmodified PKS dosage on the sorption of nitrate.

\begin{tabular}{cccc}
\hline Sorbent dosage & $\mathrm{q}_{\mathrm{m}}$ & $\mathrm{K}_{\mathrm{L}}\left[\mathrm{mg}^{-1}\right]$ & $\mathrm{r}^{2}$ \\
\hline 0.2 & 60.12 & 0.9674 & 0.9457 \\
0.4 & 51.51 & 0.9782 & 0.9672 \\
0.6 & 33.24 & 0.9971 & 0.9683 \\
0.8 & 21.57 & 1.0756 & 0.9742 \\
1.0 & 15.22 & 1.1254 & 0.9822 \\
\hline
\end{tabular}

\section{Conclusion}

The equilibrium isotherm analysis was used to study the capacity of the modified and unmodified PKS to adsorb nitrate from aqueous medium. The experimental results indicated that both sorbents can be successfully used for the adsorption of the nitrate ion from aqueous solution but the capacity of the modified PKS is higher than the unmodified PKS. Experimental parameters such as nitrate solution $\mathrm{pH}$ and sorbent dose must be optimally selected to obtain the highest possible removal of nitrate ion. As revealed by the results, nitrate sorption onto both sorbents decreases with increase in $\mathrm{pH}$ of the nitrate solution. Also increase in the sorbent dose at fixed nitrate concentration caused a reduction in the amount of nitrate sorbed due to an increase in the large number of sites that are ready for nitrate adsorption. The process variable optimization results also indicated that modified PKS has higher adsorption capacity than unmodified PKS within the $\mathrm{pH}$ of the nitrate and adsorbent dosage studied. The sorption of nitrate onto both adsorbents was best described by Langmuir, Freundlich and Halsey isotherm equation. In summary, modified and unmodified palmkernel shells which are waste material can be a good adsorbent for the purification of municipal wastewater stream. 


\section{References}

[1] C.A. Pigott, China in the world economy: The domestic policy challenges. OECD Publishing, 2002.

[2] C.M. Hogan, Water pollution, Encylopedia of earth topic, Washington, DC, Cleveland National Council on Science and Environment, 2010.

[3] A. Mazeikiene et al., Removal of nitrates and ammonium ions from water using sorbent zeolite (clinoptitolite), Journal of Environmental Engineering and Landscape Management. 16(1) (2008) 38-44.

[4] H. Bouwer, Agricultural contaminants, problems and solutions, Water Environment and Technology. 1(2) (1989) 292- 297.

[5] S. Samatya et al., Removal of nitrate from aqueous solution by nitrate selective ion exchange resins, Reactive and Functional Polym. 66(11) (2006) 1206-1214.

[6] N.B. Ladimir, Environmental Chemistry: Asian Lessons, New York, Boston, Dordrecht, London, Moscow, Kluwer Academic Publishers, 2003.

[7] A.O. Eruola, I.O. Ogunyemi, Evaluation of the Adsorption Capacity of the Coconut Shell and Palm-Kernel Shell Adsorbents Powder for the Sorption of Cadmium (11) Ions from Aqueous Solution, Journal of Environmental Science, Toxicology and Food Technology. 8(6) (2014) 55-63.

[8] M. Horsfall, A.L. Spiff, A.A. Abia, Studies on the influence of mercaptoacetic acid (MAA) modification of cassava (manihot sculenta cranz) waste biomass on the adsorption of $\mathrm{Cu} 2+$ and Cd 2+ from aqueous solution, Bulletin of the Korean Chemical Society. 25(7) (2004) C. 969-976.

[9] J. Crittenden et al., Water Treatment: Principles and Design, John Wiley and Sons, 2005.

[10] N.A. Oladojaa et al., Sorption of $\mathrm{Cu}$ (II) ion from aqueous solution by scrap tyre, Desalination and Water Treatment. 16 (2010) 83-94.

[11] K.A. Krishnan, T.S. Anirudhan, Removal of cadmium(II) from aqueous solutions by Steam activated sulphurised carbon prepared from sugar-cane bagasse pith: kinetics and equilibrium studies, Water SA. 29 (2003) 147-156.

[12] K.S. Low, C.K. Lee, S.C. Liew, Sorption of cadmium and lead from aqueous solutions by spent grain, Process Biochemistry. 36 (2000) 59-64.

[13] T.K. Naiya, A.K. Bhattacharya, S.K. Das, Adsorptive removal of $\mathrm{Cd}(\mathrm{II})$ ions from aqueous solutions by rice husk ash, Environmental Progress in Chemical Engineering. 28 (2009) 535546.

[14] F.E. Okieiman, E.V. Okundla, D.E. Ogbeifun, Sorption of cadmium and leadions on modified groundnut (Arachis hypogea) husks, Journal of Chemical Technology and Biotechnology. 51 (1991) 97-103.

[15] L. Nouri et al., Batch sorption dynamics and equilibrium for the removal of cadmium ions from aqueous phase using wheat bran, Journal of Hazardous Material. 149(1) (2007) 115-125.

[16] N.A. Oladoja, C.O. Aboluwoye, Y.B. Oladimeji, Kinetics and Isotherm Studies on Methylene Blue Adsorption onto Ground Palm Kernel Coat, Turkish J. Eng. Env. Sci. 32 (2008) 303312.

[17] R.B. Larley, F. Acqual, Developing national capability for manufacture of activated carbon from agricultural waste, Ghana Eng. 19(1) (1999) 1-2.

[18] M.J. Rosen, Surfactant and interfacial phenomenon, John Willey, New York, 1978. 
[19] O. Zanella, I.C. Tessaro, L.A. Feris, Nitrate Sorption on activated carbon modified with $\mathrm{CaCl}_{2}$, Chem. Ind. Chem. Eng. Q. 21(1) (2015) 23-33.

[20] M. El Ouardi et al., Effective Removal of Nitrates Ions from Aqueous Solution Using New Clay as Potential Low-Cost Adsorbent, Journal of Encapsulation and Adsorption Sciences, 5(4) (2015) 178-190.

[21] C.H. Giles et al., Studies in adsorption. Part XI. A system of classification of solution adsorption isotherms, and its use in diagnosis of adsorption mechanisms and in measurement of specific surface areas of solids, Journal of the Chemical Society. (1960) 3973-3993.

[22] C. Namasivayam, D. Sangeetha, Removal and recovery of nitrate from water by $\mathrm{ZnCl} \sim 2$ activated carbon from coconut coir pith, an agricultural solid waste, Indian J. Chem. Technol. 12(5) (2005) 513-521.

[23] R. Chitraker et al., Selective adsorption of phosphate for Seawater and wastewater by amorphous zirconium hydroxide, Journal of colloid and interface science. 297(2) (2006) 426433.

[24] A. Shukla et al. The role of sawdust in the removal of unwanted materials from water, Journal of Hazardous Materials. 95(1-2) (2002) 137-152.

[25] L.J. Yu et al., Adsorption of chromium from aqueous solutions by maple sawdust, Journal of Hazardous Materials. 100(1-3) (2003) 53-63. 